\title{
Efficient Method of Producing Oval Punching holes on Sheet Metal
}

\author{
Vyankatesh B. Emche* and Rajesh R Kandalkar
}

Department of Mechanical Engineering, G.H.Raisoni College of Engineering, Nagpur, India

\begin{abstract}
As method for punching in oval shapes is not readily available, press tool for punching in oval shapes is required in various industries according to their applications.

There are press tools for punching in circular shape, but when shapes other than circular shape are desired, they have to design according to dimensions required by industry.

As application for oval shape punching differs from industry to industry because dimensions required by industries differ from each other. As some industries require more than one oval shaped hole that is to be done in single stroke for reducing the time required for production, there is need to design such press tool which can perform such operation.

Hence to have fast production of required oval size holes, there is need to develop a press tool assembly which can make accurate oval holes on metal sheets. For designing such assembly, it is very necessary to study every aspect of existing design of press tool so that changes required can be easily define. Comparison of existing design with the proposed enables us to find correct way of design.
\end{abstract}

Keywords: Punching tool; Oval punching; Sheet metal; Sheet metal manufacturing; Sheet metal features; Selection of material

\section{Introduction}

Punching process is increasingly used in manufacture industry. Punching is among the most important sheet metal in manufacturing process in mass production of metal parts and components. This operation has a great impact in variety of industries such as automotive industry. In recent years, a further understanding of the technological aspects of the punching process has been gained especially in punching tools [1].

- Punching is the most cost effective process of making holes in strip or sheet metal for average to high fabrication

- It is able to create multiple shaped holes

As method for punching in oval shapes is not readily available, press tool for punching in oval shapes is required in various industries according to their applications.

There are press tools for punching in circular shape, but when shapes other than circular shape are desired, they have to design according to dimensions required by industry.

The cost of tooling in sheet metal industries contributes a considerable part to the overall cost of manufacturing a component. It is therefore imperative to keep down this cost by ensuring that the tool works for a long period in production without interruption. One way of achieving this objective is to reduce the stress on the tool during punching.

3-D finite-element models of various types of punching/blanking tools have been developed, these models enabling the analysis of the effects of variations in tool geometry on the punching/blanking force and on the deformation of the punch, a parameter highly relevant to the assessment of tool performance in terms of the accuracy of the manufactured components. The model caters also for variation in the characteristics of the tool material, in the sense that a highly wearresistant tool is normally composed of carbide tips around its cutting profile [2].
Clearance plays important role in Punch design. A good clearance design not only increases the quality of product manufactured, but also reduces product's burr [3].

Hence it implies that there is need to design such press tool which can punch different shape than conventional type of punching and which can withstand stresses acting and can run for long life.

\section{Feature classification in punching holes in sheet metal}

The classification of cutting and punching is a seven-stage process. Each stage involves making a number of choices regarding the product. These choices should be made based on shapes and features created in the design stage. It is thus a step-by-step process towards the selection of a manufacturing method. All conditions involved are finally compared to the possibilities of the processes. Based on the comparison, certain manufacturing processes are proposed to the user for manufacturing the part in question. At this point, the choice is based solely on technological aspects. Cost factors, which play an important role in the process selection, can be involved in the comparison after that.

The grounds for rejection and approval should be carefully examined, because the system is a good servant when it functions well but a bad one when it does not. It may lead to choosing the wrong solutions merely because the system recommends them. On the other hand, the system may be used very little or not at all if users consider its proposals irrational.

There are many manufacturing methods for edges and holes in sheet metal parts. Each process has a number of variables and parameters that impact manufacturability.

*Corresponding author: Vyankatesh B. Emche, Research Scholar, Departmen of Mechanical Engineering, G.H.Raisoni College of Engineering, Nagpur, India, Tel: +919860042612; Email: vemche@gmail.com

Received April 09, 2012; Accepted June 15, 2012; Published June 18, 2012

Citation: Vyankatesh BE, Rajesh RK (2012) Efficient Method of Producing Oval Punching holes on Sheet Metal. J Appl Mech Eng 1:109. doi:10.4172/2168-9873.1000109

Copyright: @ 2012 Vyankatesh BE, et al. This is an open-access article distributed under the terms of the Creative Commons Attribution License, which permits unrestricted use, distribution, and reproduction in any medium, provided the original author and source are credited. 
These variables, in turn, are affected by several features of the part, such as material or the location of bends and holes. Due to the above, the operation of the system and its functions and logic should be carefully prepared and their validity ensured from as many viewpoints as possible [4].

\section{Development of system for selection of materials for press tool}

Metal stampings are important structural components of automobiles, computers, refrigerators, type writers, kitchen utensils, electrical, electronics and telecommunication equipments.

Sheet metal operations are economical and quick means of producing intricate, accurate, strong and durable metal stampings in huge quantities. Applications of these operations are increasing day by day due to their high productivity, low cost per part, improvement in material quality, minimum scrap material and energy consumption. One of the important tasks in the production of metal stampings is the design of press tools and selection of materials for press tool components to suit the product features. The selection of a proper material for press tool components has become one of the important aspects of press tool design because long tool life has become a necessity for achieving higher productivity and reducing cost of sheet metal parts. Traditional methods of selection of materials of press tool components are dependent on the vast experience and depth of knowledge of domain experts in the area of material science and die design. Most of the times, material selection for press tool components is carried out manually using die design handbooks, material handbooks, thumb-rules and heuristics. If all this knowledge is stored in a knowledge base system then the selection of materials will become easier as the tedious search in handbooks will be eliminated.

Most of the existing computer-aided die design systems have still not fully dealt with the core die design issue of material selection of press tool components. Some existing CAD/CAM systems are able to generate bill of materials, however these systems do not take in account the availability of other suitable materials for the choice of user for better performance of press tool components and hence the long life of press tool. Further, these systems do not have even knowledge base consisting of experienced knowledge of domain experts in material selection of press tool components. In selecting materials, designers and engineers have to take into account a large number of factors.

Worldwide researchers have stressed to apply research efforts for capturing and documenting the invaluable practical knowledge of experienced die designers and toolmakers through the applications of Artificial Intelligence (AI) techniques. The highly experience based stamping die design activities such as material selection of press tool components can be simplified by using knowledge base system or intelligent system approach. Development of such system can prove a landmark to ease the complexities involved in the process of material selection [5].

\section{Selection of materials for press tool components}

The selection of materials for press tool components for a given application depend on which die failure mechanisms dominates. It requires more than just knowledge of materials properties. The stepby-step manual process of material selection is investigated during industrial visits and discussion with die design experts and is given as under.

Step 1. Identify the type of wear: This is the most fundamental step because it will determine which wear resistance profile the die material should have.

The following factors are considered to establish the dominating wear (abrasive, adhesive or mixed) to be expected:

- Type of sheet material

- Hardness of sheet material

- Presence of hard particles in the sheet material.

Step2. Occurrence of chipping or plastic deformation: The following factors determine the extent of the risk for chipping and/or plastic deformation, i.e. whether high ductility and/or high hardness are needed:

- Type of operations to be performed on press tool

- Thickness and hardness of sheet material

- Geometrical complexity of parts to be produced.

The die designer normally uses his vast experience here.

Step 3. Risk of cracking: The following factors give an indication of the risk for cracking, i.e. whether tough material and/or moderate hardness levels have to be used:

- Type of operations to be performed on press tool

- Geometry of part to be produced

- Die design and die size

- Thickness and hardness of sheet material

\section{Acquisition of the domain knowledge}

The technical knowledge for the development of proposed system was collected through interviewing experienced die designers and tool manufacturers; studying die design handbooks, relevant industrial brochures and technical reports. The knowledge of selection of materials of press tool components in form of data, facts and judgments was obtained from experienced die designers and tool manufacturers by holding discussions on typical problems and letting them talk about the approach and rules of thumb relied upon by them. During the verbal analysis, they were questioned to explain why a particular material was selected for specific die component. This was accomplished to identify the factors influencing the selection of materials of press tool components.

\section{Challenges in Oval punching by Press Tool}

Nowadays, CNC punching machine have been used to fabricate the product from sheet metal where the process is fully under computer controlled with preparing NC program. The technology in cutting process improve day by day rapidly which have plasma cutting, laser cutting, turret punch and etc.. Different type of machine, it will conduct different but same of basic.

Tool system is very important in machining process. Complete tool set contain punch, alignment ring, stripper and die. If one of these components not conducts wisely it will damage the product or will facing with machine damage. To sure the product is high quality and the process of manufacture can conduct safely, the quality of punch component especially tooling is very important. Punch is come in three designs which are flat punch, punch with roof shear and angled punch. 
Better tool is defined as strength of wear resistance and toughness in better quality and which is appropriate to use for respective application.

Experience shows that cost of tooling in sheet metal industries contributes a substantial part to the overall cost of manufacturing a component, so that it is essential to keep down this cost by ensuring that the tool works for a long period without interruption.

There are oval shape punch die set are available in market which helps you to produce oval / ellipse shape tablets. Normally oval shape punch die sets are applicable to pharmaceutical and ayurvedic industries. These punch die sets are available with different size, concavity, and flat in plain or engraved break line.

Oval punching on metals is task which required skills if it will be performed without using Computer Numerical controlled machines, and it will be tedious process which takes lot of time.

Hence to have fast production of required oval size holes, there is need to develop a press tool assembly which can make accurate oval holes on metal sheets. In Most of industries the common material used for metal sheets is high carbon steel which is not so easy to machine.

Hence press tool to be designed must be of such material which can perform machining on materials like high carbon steel. So alloying elements like chromium combined with high carbon steel will be useful for such applications.

Problems occurring in today's scenario for punching in oval shapes are:-

- Unavailability of press tool to create oval shaped hole.

- Life of press tool.

There are not many press tools available for punching in oval shapes in today's scenario.

As application for oval shape punching differs from industry to industry because dimensions required by industries differ from each other. As some industries require more than one oval shaped hole that is to be done in single stroke for reducing the time required for production, there is need to design such press tool which can perform such operation.

Press tool should be such that it can withstand stresses acting on it during operation and can run for long life.

\section{Development of tool assembly for oval punching}

For making a press tool for oval punching, steps involved are:

- Analytical design for press tool.

- 3 - D Modeling in PRO - ENGINEER Wildfire 5.0

- Assembly

- Analysis by using ANSYS.

- Program generation by PRO - ENGINEER Wildfire 5.0

- Import a program to CNC Machine.

Actual manufacturing according program generated will start. For this project, it is very necessary to study every aspect of existing design of press tool so that changes required can be easily define. Comparison of existing design with the proposed enables us to find correct way of design.

\section{Functions of each part in press tool assembly (Figure 1)}

Top plate: It prevents the punches to dismantle from assembly

Punching Plate: It comprises of four punches attached in it tightly which performs basic punching operation.

Stripper Plate: This plate is fixed with punching plate to enabled easier ejecting of assembly and also tightens and guides the press tool to the metal sheets.

Spacer: It is provided to prevent the direct contact of stripper plate and die plate for their longer life

Die plate: It is the plate where actual cutting action takes place. It is provided with Taper to remove the metal punched out easily.

Bottom Plate: It gives the support to the assembly and guides the proper way of metal waste.

\section{Design of Punch}

As oval geometry required on metal sheet is as follows (Figure 2)

- Tonnage Capacity of Press: 150 Tons

- Press normally set on 75 Tons and operation Continues on that capacity.

- Material of Punch: High carbon high Chromium Steel

- Material of Steel Sheet to Punch: Low carbon CR (cold Rolled) Sheet

* The Force required to Cut (shear) work Material is,

Force $=\mathrm{S}^{\star} \mathrm{Ls}^{*} \mathrm{t}$------- (For irregular contours)

Where, $\mathrm{S}=$ Shear Strength of Material $\left(\mathrm{N} / \mathrm{mm}^{2}\right)$

Ls $=$ Shear Length $(\mathrm{mm})$

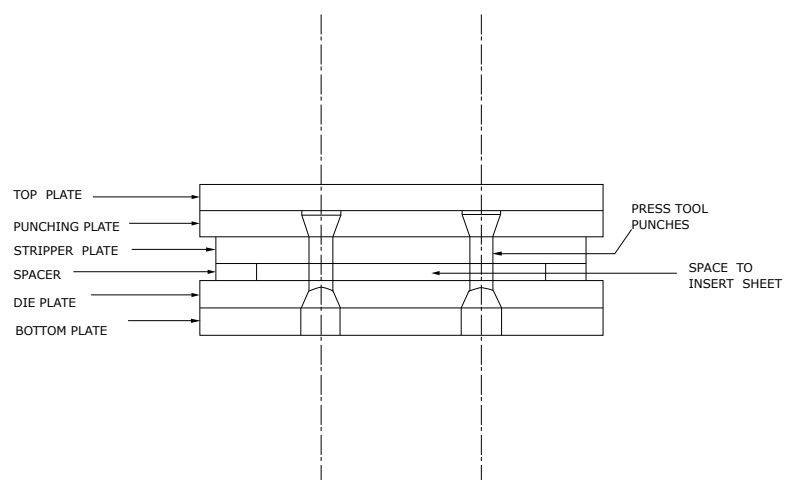

Figure 1: Figure Of Press Tool Assembly.
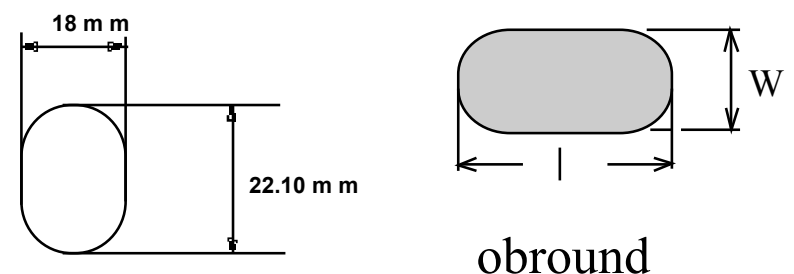

Figure 2: Oval geometry required on metal sheet. 
$\mathrm{t}=$ Material Thickness $(\mathrm{mm})[6]$

For low carbon CR steel sheet shear strength $=40000 \mathrm{psi}=275.79$ $\mathrm{N} / \mathrm{mm}^{2}$

$$
\begin{aligned}
\text { Ls }= & \text { Shear Length }=\left(\pi^{*} \mathrm{w}\right)+2 *(1-\mathrm{w}) \\
& =\left(\pi^{\star} 18\right)+2 *(22.10-18) \\
& =64.74 \mathrm{~mm}
\end{aligned}
$$

Material Thickness $=4 \mathrm{~mm}$

$\mathrm{F}=275.79 * 64.74 * 4$

$\mathrm{F}=71418.5784 \mathrm{~N}$

\section{1 tonne $=9806.65 \mathrm{~N}$}

Tonnage capacity needed for the Job 7.28 tonne.

For 4 punches to operate on same time tonnage capacity $=4{ }^{\star} 7.28$ i.e. 29.13 tonne

As press is operating on 75 tonnes, requirement of punching oval hole is fulfilled.

Actual Force acting on single Punch is 7.28 Tonne i.e. $71392.412 \mathrm{~N}$

* Critical Distance A as shown in figure 3 between cutting edge and die border must not be less than 1.5 or 2 times of die thickness---(Statement I)

In this case die thickness is $30 \mathrm{~mm}$.

And critical distance A is $200 \mathrm{~mm}$ as four punches working on same time. Hence Statement I is satisfied. [6]

\section{* Punch dimensions}

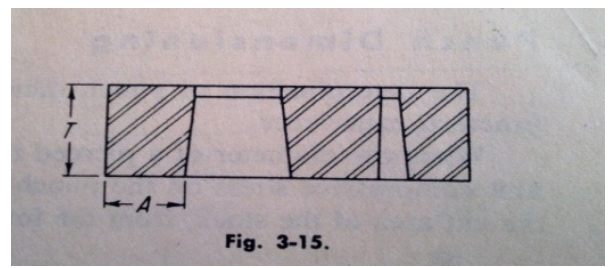

Figure 3: Critical Distance.
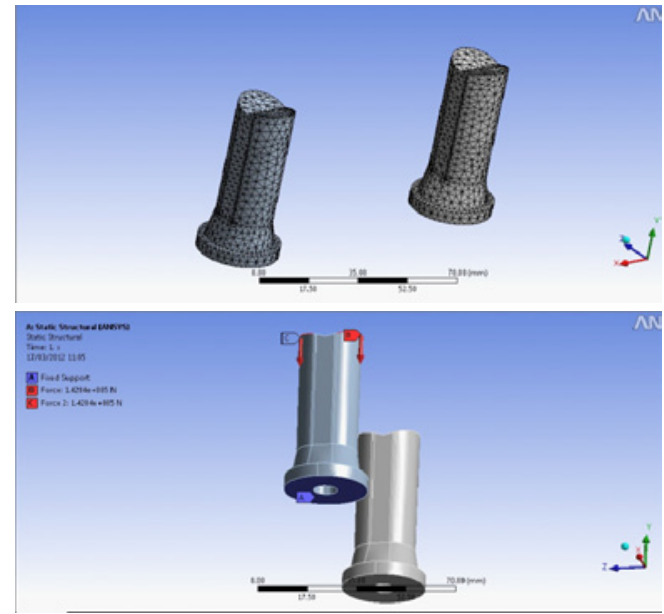

Figure 4: Ansys Analysis.
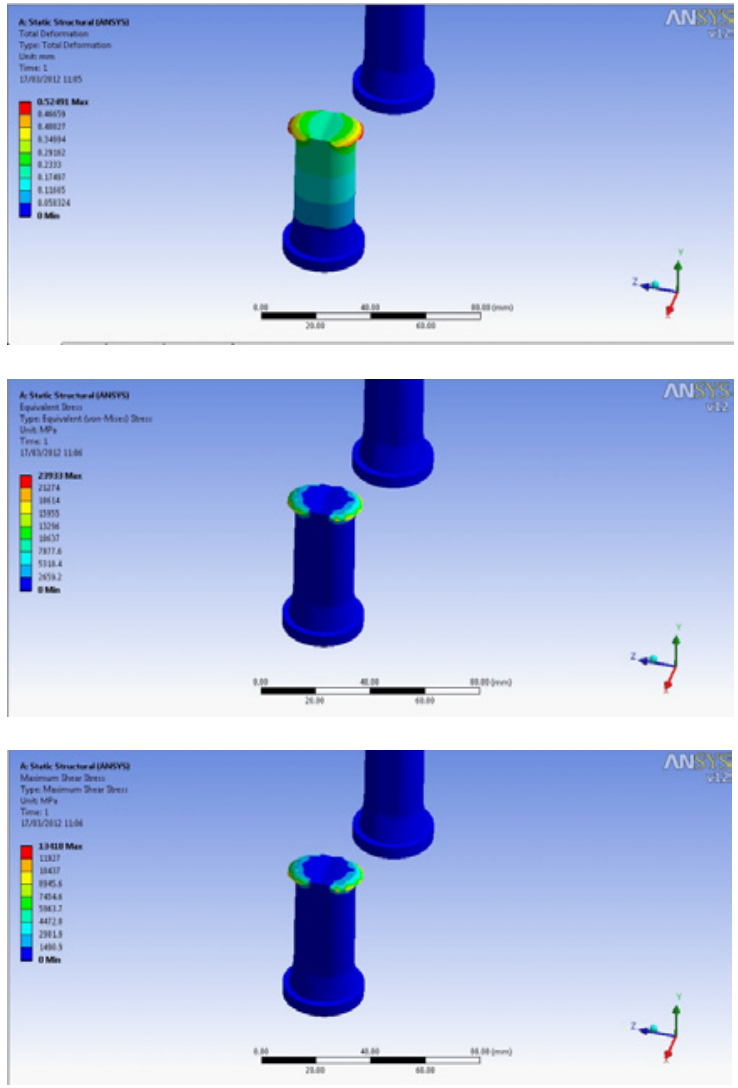

Figure 5: Analysis of punch in Ansys workbench 12.

The determination of Punch dimensions has been generally based on practical experience.

The maximum allowable Length of Punch can be calculated from formula

$$
L=\left(\frac{L s}{8}\right) *\left(\left(\frac{E}{S}\right) *\left(\frac{d}{t}\right)\right)[7]
$$

Where Ls $=$ Shear length $=64.74 \mathrm{~mm}$

$\mathrm{E}=$ Modulus of Elasticity of work material

$=2 * 10^{5} \mathrm{~N} / \mathrm{mm}^{2}$

Therefore the Maximum allowable length of Punch can be used is $\mathrm{L}=474 \mathrm{~mm}$

In this case Punch length selected is $63 \mathrm{~mm}$ according to assembly developed.

* Calculation of Punches

Good Practice requires 10 percent of the metal thickness to be removed from basic dimension of Punch.

So basic dimension of punch is $22.10 \mathrm{~mm}$

Stock Thickness $=4 \mathrm{~mm}$

$10 \%$ of thickness $=0.4 \mathrm{~mm}$

Punch $=22.10--0.4=22.06 \mathrm{~mm}$ 
Therefore Punch will provided by clearance of $+0.4 \mathrm{~mm}$

For die opening the same $10 \%$ of Metal thickness clearance is provided

i.e $+0.4 \mathrm{~mm}[7]$

* Actual Force acting on single Punch is 7.28 Tonne

i.e $71392.412 \mathrm{~N}$

Selecting factor of Safety 2

Analyzing the punch for $142784 \mathrm{~N}$ by using Ansys workbench 12 (Figure 4)

Steps of Analysis

$>$ Import model in iges format in Ansys workbench 12

$>$ Divide the model in elements by meshing

Apply the force

$>$ Solve for stress calculation

\section{Conclusion}

From the simple observation that behind each shape of a sheet metal product lays a restricted group of machines, we can deduce that sheet metal shapes can be classified into manufacturing features. Thus, each shape or feature corresponds to a feature class or feature. By preparing rules and restrictions for the feature classes and features, the design of sheet metal products can be made more manufacturing friendly.

Knowledge for selection of materials of press tool components obtained from die designers, tool manufacturers, die design handbooks and industrial brochures has been analyzed, tabulated and incorporated into a set of production rules. The procedure of development of proposed intelligent system has been described at length. The system is capable of giving expert advice on selection of materials of active \& inactive components of press tool.

There are not many press tools available for punching in oval shapes in today's scenario. As application for oval shape punching differs from industry to industry because dimensions required by industries differ from each other. As some industries require more than one oval shaped hole that is to be done in single stroke for reducing the time required for production, This simple design of Press Tool assembly enables to perform such operation with safety and less possibilities of scrap.

After analyzing the punch in Ansys workbench 12 (Figure 5), results shows that there is less stress developing in punch that ensuring this design is safe.

\section{References}

1. Mohd Khairul Mizan Bin Nasir (2009) Investigate the effect of shear angle of high speed steel punching tool in punching process. Thesis, Faculty of Mechanical Engineering, Universiti Malaysia Pahang.

2. U.P. Singh (1992) Design study of the geometry of a punching/ blanking tool Journal of Materials Processing Technology 33: 331-345.

3. J. Ch. Lin, WS Lin, KS Lee, JL Tong (2008) The optimal clearance design of micro-punching die. Journal of Achievements in Materials and Manufacturing Engineering 14

4. M.Lohtander, J. Varis. Manufacturing Features In Cutting Shapes And Punching Holes In Sheet Metal. 19th International Conference on Production Research, Department of mechanical engineering, Lappeenranta University of Technology, Lappeenranta, Finland

5. S. Kumar (2011) An Intelligent System for Selection of Materials for Press Too Components. Journal of Engineering Research and Studies 2: 119-130.

6. 'Fundamental of Tool Design' by American Society of Tool and manufacturing engineers.

7. 'Tool design' by Cyril Donaldson Tata mcgraw hill third edition. 